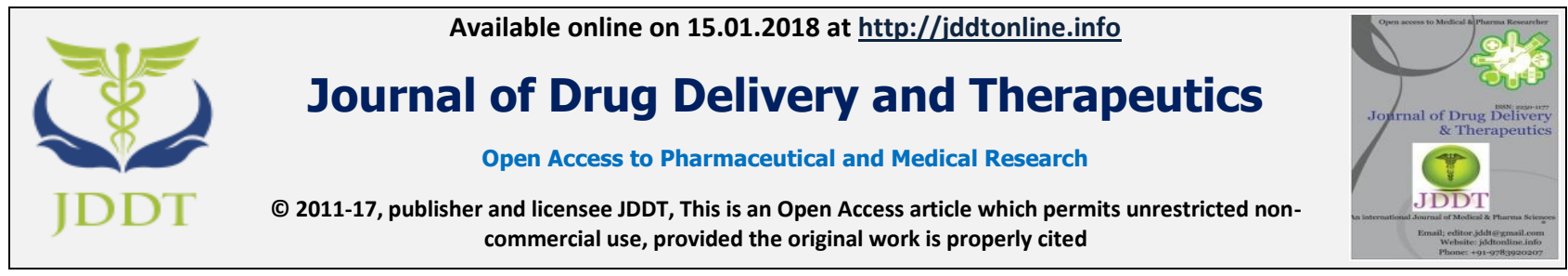

Open $\odot$ Access

Research Article

\title{
EVALUATION OF COMPRESSION PROCESS VARIABLES FOR MULTIUNIT PARTICULATE SYSTEM (MUPS) TABLET BY QbD APPROACH
}

\author{
C. Pradeep Kumar Reddy ${ }^{1}$, Chakka Gopinath ${ }^{2}$ \\ ${ }^{1}$ Graviti Pharmaceuticals Private Limited, Survey No. 621/E \& 621/EE, Isnapur Village, Patancheru Mandal, \\ Sangareddy - 502 307, Telangana, India \\ ${ }^{2}$ Annamacharya College of pharmacy, Rajampet, YSR Kadapa (Dt), 516216, Andhra Pradesh, India
}

\section{ABSTRACT}

Objective: The objective of the study was to evaluate and optimize compression process variables of Esomeprazole (Multiunit particulate system) MUPS tablet.

Materials and methods: A three-factor, two-level, full factorial design was used to investigate the influence process variables Viz. Main compression force, Pre-compression force and Turret speed. Responses studied were Weight variation, Hardness, Thickness, Friability, Content uniformity, Drug release in $0.1 \mathrm{~N} \mathrm{HCl}$ at $120 \mathrm{~min}$ and drug release in $\mathrm{pH} 6.5$ simulated intestinal fluid at 15 min.

Results and discussion: Main compression force and the Pre-compression force had a significant influence on hardness, thickness, drug release in $0.1 \mathrm{~N} \mathrm{HCl}$ at $120 \mathrm{~min}$ and drug release in $\mathrm{pH} 6.5 \mathrm{SIF}$ at $15 \mathrm{~min}$. Higher compression force leads to breakage of pellets during compression which showed impact drug release at acid stage. Turret speed had significant impact on final weight variation and content uniformity. The optimized process parameters Main compression force: $11.33 \mathrm{kP}$, Pre-compression force: $2.72 \mathrm{Kp}$ and Turret speed: $23.56 \mathrm{rpm}$ showed desired physical characteristics and drug release in $0.1 \mathrm{~N} \mathrm{HCl}$ which will result in lesser degradation of API at acid stage.

Conclusion: It is concluded that Compression process variables in preparation of Esomeprazole MUPS were successfully evaluated using Design of Experiment approach.

Keywords: process variables, Esomeprazole, Multiunit particulate system

Article Info: Received 11 Nov, 2017; Review Completed 07 Jan, 2018; Accepted 08 Jan, 2018; Available online 15 Jan, 2018

\section{G:Trar. Cite this article as:}

C. Pradeep kumar Reddy, Senior General Manager, Graviti Pharmaceuticals Private Limited, Survey No. 621/E \& 621/EE, Isnapur Village, Patancheru Mandal, Sangareddy - 502 307, Telangana, India. Tel: +91-7680882447, Email: pradeepkr@gravitipharma.com, Journal of Drug Delivery and Therapeutics. 2018; 8(1):48-56

DOI: http://dx.doi.org/10.22270/jddt.v8i1.1554

*Address for Correspondence

Gopinath C, C. Reddy PK, Evaluation of compression process variables for multiunit particulate system (MUPS) tablet by qbd approach

\section{INTRODUCTION}

Solid oral controlled and modified release drug delivery systems are the most acceptable and reliable dosage form to patients. Multi-particulate systems (MUPS) are mainly oral dosage forms consisting of a multiplicity of small discrete units, each exhibiting some desired characteristics. In these systems, the dosage of the drug substances is divided on a plurality of subunit, typically consisting of thousands of spherical particles ${ }^{1}$. MUPS offer various advantages over other systems, including reduced risk of local irritation and toxicity, predictable bioavailability, reduced likelihood of dose dumping, minimized fluctuations in plasma concentration of drug, and high dose-strength administration ${ }^{2}$.

Compression of pellets is a major challenge which involves segregation of pellets in hopper as well as on turret. Turret speed may lead to segregation of pellets which may have impact on final DP-CQA's Assay, drug release and content uniformity of tablets ${ }^{\mathbf{3 , 4}}$. Other factors that may have impact on DP-CQAs are size, shape and density of pellets, nature of polymer and polymer coating, amount of polymer coating and nature and amount of extra-granular excipients ${ }^{5-8}$. 
Esomeprazole Magnesium selected as model drug for study, which belongs to Proton pump inhibitors class. Proton pump inhibitors are potent inhibitors of acid secretion. These compounds are susceptible to degradation in acid media. Therefore, formulation was prepared using enteric coating polymers and finally compressed into MUPS tablet to avoid degradation of drug in acidic $\mathrm{pH}$ and irritation to gastric mucosa.

Experimental design and statistical modelling are essential tools for the development and understanding of complicated formulations and processes. Design of experiment (DoE) approach can be used to understand impact of formulation factors/process variables. Further it allows efficient experimentation covering a large number of factors which are varied together over a set of experiments, in contrast with the traditional approach of varying each factor while keeping other factors constant, which may fail to identify any interactions between these factors $9,10,11$. In current study, a computer-aided optimization technique using a three factor, two-level, full factorial design was used to investigate the effect of three process variables, i.e., Main compression force, Pre-compression force, and Turret speed.

\section{MATERIALS \& METHODS}

\section{Materials}

Esomeprazole Magnesium was obtained as a gift sample from Hetero Drugs. Ludipress LCE and Crospovidone (Kollidon CL-F) was gifted from BASF. Prosolv SMCC HD 90, Prosolv SMCC 90 and Sodium stearyl fumarate were obtained from JRS Pharma. PEG 6000 was obtained from Sigma Aldrich. All the chemicals and reagents were of analytical reagent (AR) grade and used without further purifications.

Methods

\section{Preparation of lubricated blend}

All extra granular excipients were sifted through 30 mesh (Table 1). Esomeprazole Magnesium over coated pellets with Prosolv SMCC HD 90 were co-sifted through 30 mesh, labelled as co-sift I. Crospovidone, PEG 6000 and 1/2th quantity of ludipress LCE were sifted through30 mesh and labelled as co-sift II. Aerosil with remaining quantity of ludipress LCE were sifted through 30 mesh, labelled as co-sift III. Initial pre-sifted Prosolv SMCC 90 added to double cone blender followed by co-sift I, co-sift II, co-sift III and mixed for 10 min with $10 \mathrm{rpm}$.
Table 1: Composition details for Esomeprazole Magnesium MUPS tablets

\begin{tabular}{|c|l|c|}
\hline $\begin{array}{l}\text { Sr. } \\
\text { No. }\end{array}$ & Ingredients & Mg/tab \\
\hline 1 & Top coated pellets & 263.28 \\
\hline 2 & Ludipress LCE & 280.96 \\
\hline 3 & Prosolv SMCC HD 90 & 135.00 \\
\hline 4 & Prosolv SMCC 90 & 135.00 \\
\hline 5 & PEG 6000 & 70.00 \\
\hline 6 & Crospovidone & 20.00 \\
\hline 7 & Sodium stearyl fumarate & 6.00 \\
\hline 8 & Colloidal silicon dioxide (Aerosil 200) & 4.00 \\
\hline & Total & $\mathbf{9 1 4 . 2 4}$ \\
\hline
\end{tabular}

\section{Compression}

Tablets were compressed using Protab 21station compression machine having unit weight $914.24 \mathrm{mg}$ (Tooling Details: 19.3*9.7mm, oval shaped). Compression parameters evaluated ranges shown in table 2 .

\section{Experimental design}

A number of preliminary experiments were conducted to determine the critical process variables by which the process resulted in quality of MUPS. Design Expert software was used in our study for generation and evaluation of the statistical experimental design. A three-factor, two-level, full factorial design was employed for the optimization procedure. The main compression force $\left(\mathrm{X}_{1}, \mathrm{kN}\right)$, Pre-compression force $\left(\mathrm{X}_{2}\right.$, $\mathrm{kN})$, and Turret speed $\left(\mathrm{X}_{3}, \mathrm{rpm}\right)$ were selected as the independent variables, whereas Weight variation $\left(\mathrm{Y}_{1}\right)$, Hardness $\left(\mathrm{Y}_{2}\right)$, Thickness $\left(\mathrm{Y}_{3}\right)$, Content uniformity $\left(\mathrm{Y}_{4}\right)$, Drug release in $0.1 \mathrm{~N} \mathrm{HCl}$ at $2 \mathrm{hrs}\left(\mathrm{Y}_{5}\right)$, and drug release in $\mathrm{pH} 6.5$ simulated intestinal fluid at $15 \mathrm{~min}\left(\mathrm{Y}_{6}\right)$ were chosen as the dependent variables. Table 2 summarizes these process variables with corresponding levels and the responses studied, whereas experimental runs with different process variables are listed in Table 3. The variables were selected to measure the change in response from one extreme factor to another and for determining interactions, if any, among the factors with their best levels for optimizing the considered experimental responses.

Table 2: Three Factor, two level Full Factorial Experimental Design: Factors selected and responses measured

\begin{tabular}{|c|c|c|c|}
\hline \multirow{2}{*}{ Factors (Process variables) } & \multicolumn{2}{|c|}{$\begin{array}{c}\text { Levels of factors used in } \\
\text { process optimization studies }\end{array}$} & Responses to be studied \\
\hline & -1 & 1 & \multirow{4}{*}{$\begin{array}{l}\mathrm{Y}_{1}: \text { Weight variation - \% RSD } \\
\mathrm{Y}_{2:} \text { Hardness, } \\
\mathrm{Y}_{3} \text { : Thickness } \\
\mathrm{Y}_{4}: \text { Content uniformity } \\
\mathrm{Y}_{5} \text { Drug release in } 0.1 \mathrm{~N} \mathrm{HCl} \text { at } 2 \mathrm{hrs} \\
\mathrm{Y}_{6}: \text { Drug release in } \mathrm{pH} 6.5 \text { simulated } \\
\text { intestinal fluid at } 15 \mathrm{~min} .\end{array}$} \\
\hline $\begin{array}{l}\text { Main compression force } \\
\left(\mathrm{X}_{1}, \mathrm{kN}\right)\end{array}$ & 9 & 13 & \\
\hline $\begin{array}{l}\text { Pre-compression force } \\
\left(\mathrm{X}_{2}, \mathrm{kN}\right),\end{array}$ & 2 & 4 & \\
\hline Turret speed $\left(\mathrm{X}_{3}, \mathrm{rpm}\right)$ & 15 & 45 & \\
\hline
\end{tabular}


Table 3: Esomeprazole Magnesium MUPS tablet compression variables as per $2^{3}$ Full Factorial Experimental Design

\begin{tabular}{|c|c|c|c|}
\hline Run & $\begin{array}{c}\text { Process Variable } \mathbf{X}_{\mathbf{1}} \\
\text { (Main compression force, } \mathrm{kN})\end{array}$ & $\begin{array}{c}\text { Process Variable } \mathbf{X}_{\mathbf{2}} \\
(\text { Pre-compression force, } \mathrm{kN})\end{array}$ & $\begin{array}{c}\text { Process Variable } \mathbf{X}_{\mathbf{3}} \\
\text { (Turret speed, rpm) }\end{array}$ \\
\hline RUN 1 & 13 & 2 & 45 \\
\hline RUN 2 & 9 & 2 & 45 \\
\hline RUN 3 & 13 & 2 & 15 \\
\hline RUN 4 & 9 & 4 & 45 \\
\hline RUN 5 & 9 & 4 & 45 \\
\hline RUN 6 & 13 & 4 & 15 \\
\hline RUN 7 & 13 & 4 & 15 \\
\hline RUN 8 & 9 & 2 & 45 \\
\hline
\end{tabular}

\section{Physicochemical Characterization of Esomeprazole MUPS tablet}

\section{Dissolution studies}

Dissolution studies were carried out in two stages. Dissolution in acidic condition i.e., $0.1 \mathrm{~N} \mathrm{HCl}$ for $2 \mathrm{hrs}$ with volume $500 \mathrm{~mL}$, USP apparatus II (Paddle)and temperature $37 \pm 0.5^{\circ} \mathrm{C}$ followed by dissolution in $\mathrm{pH}$ 6.5 , simulated intestinal condition for $45 \mathrm{~min}$ with volume $500 \mathrm{~mL}$, USP apparatus II (Paddle) and temperature $37 \pm 0.5^{\circ} \mathrm{C}$.

\section{Content uniformity - AV value}

Content uniformity was evaluated by USP method (905) and acceptance value (AV) calculated at different turret speed and compression force.

\section{Weight variation - \% RSD}

Weighed individually 20 tablets selected at random and calculated the average weight. Study repeated three times for each formulation $(n=3)$. Weighing balance used Mettler Toledo.

\section{Hardness}

Tablet hardness was measured from the force required to fracture tablets by diametrical compression using a tablet hardness Tester (Erweka TBH200, Germany). Mean hardness of 10 tablets from each formulation was observed and reported as tablet hardness $(n=10)$.

\section{Friability}

Friability of tablets was determined using Friabilator (Electrolab, India). Ten tablets were added in a friabilator at $25 \mathrm{rpm}$ and dropping. The percent friability was then calculated by,

\section{Percent Friability $=(\mathrm{W}-\mathrm{Wo} / \mathrm{W}) \times 100$}

Where, Wo is the weight of the tablets before the test and $\mathrm{W}$ is the weight of the tablet after the test.

\section{Statistical Analysis}

Design Expert software was used for generation of polynomial models, including interaction terms for all response variables using multiple linear regression analysis. Polynomial models together with interaction terms were generated for all the response variables by means of multiple linear regression analysis. The influence of various process variables and their interaction with each of the responses are represented graphically. In order to validate the polynomial equations, one optimum checkpoint and three random checkpoints were selected by intensive grid search, performed over the entire experimental domain. Values were predicted for each process variable using a mathematical model developed for the optimized process and three additional random checkpoints covering the entire range of the experimental domain. These predicted values were compared with the resulting experimental values and the percentage bias was calculated.

\section{RESULTS AND DISCUSSION}

\section{Risk Assessment and Justification}

A risk assessment of the Compression process was performed to identify the high-risk unit operations that could affect the final DP-CQAs. The process variables that could impact the identified drug product CQAs were the focus of risk assessment to determine which variables have the highest potential to cause CQA failures. These variables were then investigated in order to optimize compression process variables and mitigate the risk of failure.

The initial risk assessment of the compression process is shown in the table 4 below. Tooling design and size was fixed at initial stages of development trials hence risk considered ass Low. During preliminary trials. feeder speed was evaluated in range $15-30 \mathrm{rpm}$ and proposed during optimization studies. Hence initial risk considered as low. Pre-compression force and Main compression force may have impact on intermedia CQA hardness and thickness, which may have impact on dissolution of tablets. Higher compression force may lead to breakage of pellets which may lead to drug release in Acid medium. Hence risk considered as High for DP-CQA Dissolution. High turret speed may lead to weight variation of tablets which may have impact on DP-CQA content uniformity and assay of tablets. Hence risk considered as High. Lubricant quantity may have impact on ejection force. Lubricant used sodium stearyl fumarate was optimized during formulation evaluation and ejection force found 200-300. Hence risk considered as low. Environmental conditions were monitored during process. Hence risk considered as low. 
Table 4: Initial Risk Assessment for Compression Process Variables

\begin{tabular}{|c|c|c|c|c|c|c|c|}
\hline \multirow[b]{2}{*}{ CQA's } & \multicolumn{7}{|c|}{ Compression Process steps } \\
\hline & $\begin{array}{l}\text { Tooling } \\
\text { design }\end{array}$ & Feeder speed & $\begin{array}{l}\text { Pre-compression } \\
\text { force }\end{array}$ & $\begin{array}{c}\text { Main } \\
\text { compression } \\
\text { force }\end{array}$ & $\begin{array}{l}\text { Turret } \\
\text { speed }\end{array}$ & $\begin{array}{l}\text { Ejection } \\
\text { force }\end{array}$ & $\begin{array}{l}\text { Environmental } \\
\text { conditions }\end{array}$ \\
\hline \multicolumn{8}{|c|}{ Intermediate CQA's } \\
\hline $\begin{array}{l}\text { Weight } \\
\text { Variation }\end{array}$ & Low & Low & $\overline{\text { Low }}$ & Low & High & Low & Low \\
\hline Hardness & Low & Low & High & High & Low & Low & Low \\
\hline Thickness & Low & Low & Medium & Medium & Low & Low & Low \\
\hline \multicolumn{8}{|c|}{ Finished product CQA's } \\
\hline Assay & Low & Low & Low & Low & Low & Low & Low \\
\hline Dissolution & Low & Low & High & High & Medium & Low & Low \\
\hline $\begin{array}{l}\text { content } \\
\text { uniformity } \\
\text {-AV value }\end{array}$ & Low & Low & Low & Low & High & Low & Low \\
\hline $\begin{array}{l}\text { Water } \\
\text { content }\end{array}$ & Low & Low & Low & Low & Low & Low & Low \\
\hline $\begin{array}{l}\text { Related } \\
\text { Substances }\end{array}$ & Low & Low & Low & Low & Low & Low & Low \\
\hline
\end{tabular}




\section{Compression:}

During compression process with each run MUPS tablets were evaluated for intermediate CQAs Weight, thickness, hardness, disintegration, friability and DP-
CQAs as Content uniformity, assay and drug release. The core tablets of different batches as per design showed friability values less than $0.2 \%$, hence Friability was not included as response during evaluation. Details for eight experimental design batches and responses observed shown in table 5 .

Table 5: Result data of mean values of various responses for all the 8 batches of experimental design

\begin{tabular}{|c|c|c|c|c|c|c|c|c|c|}
\hline \multirow[t]{2}{*}{ Run } & \multicolumn{3}{|c|}{ Process Variables } & \multirow{2}{*}{$\begin{array}{c}\mathbf{Y}_{1}: \text { Weight } \\
\text { variation } \\
(\% \mathrm{RSD})\end{array}$} & \multirow{2}{*}{$\begin{array}{c}\mathbf{Y}_{2:} \\
\text { Hardness } \\
(\mathrm{kp})\end{array}$} & \multirow{2}{*}{$\begin{array}{c}\mathbf{Y}_{\mathbf{3}} \mathbf{:} \\
\text { Thickness } \\
(\mathrm{mm})\end{array}$} & \multirow{2}{*}{$\begin{array}{c}\mathbf{Y}_{\mathbf{4}} \text { : Content } \\
\text { Uniformity - } \\
\text { AV value }\end{array}$} & \multirow{2}{*}{$\begin{array}{c}\mathbf{Y}_{5:} \text { Drug } \\
\text { release in } \\
0.1 \mathrm{~N} \mathrm{HCl} \\
\text { at } 2 \mathrm{hrs}\end{array}$} & \multirow{2}{*}{$\begin{array}{c}\mathbf{Y}_{\mathbf{6}}: \text { Drug } \\
\text { release in } \mathrm{pH} \\
6.5 \text { simulated } \\
\text { intestinal fluid } \\
\text { at } 15 \mathrm{~min} .\end{array}$} \\
\hline & $\begin{array}{c}\text { Main } \\
\text { compression } \\
\text { force, } \mathrm{kN}\end{array}$ & $\begin{array}{l}\text { Pre-compression } \\
\text { force, } \mathrm{kN}\end{array}$ & $\begin{array}{l}\text { Turret speed, } \\
\text { rpm }\end{array}$ & & & & & & \\
\hline RUN 1 & 13 & 2 & $45 \div=$ & 3.42 & 18.4 & 6.89 & 5.57 & 6 & 68 \\
\hline RUN 2 & 9 & 2 & 45 & 3.14 & 11.3 & 7.2 & 6.42 & 2 & 72 \\
\hline RUN 3 & 13 & 2 & 15 & 2.16 & 18.2 & 6.86 & 3.13 & 7 & 63 \\
\hline RUN 4 & 9 & 4 & 45 & 2.83 & 11.3 & 7.18 & 6.77 & 3 & 76 \\
\hline RUN 5 & 9 & 4 & 15 & 1.67 & 12.6 & 7.16 & 1.87 & 4 & 67 \\
\hline RUN 6 & 13 & 4 & 45 & 3.59 & 19.6 & 6.82 & 7.91 & 11 & 64 \\
\hline RUN 7 & 13 & 4 & 15 & 1.93 & 19.3 & 6.8 & 2.98 & 9 & 61 \\
\hline RUN 8 & 9 & 2 & 15 & 1.23 & 11 & 7.22 & 2.51 & 3 & 74 \\
\hline RUN 9 & 13 & 2 & 45 & 3.42 & 18.4 & 6.89 & 5.57 & 6 & 68 \\
\hline
\end{tabular}

\section{Factorial design}

Experiments were carried out to determine the mathematical relationship between the process variables acting on the system and the response of the system. The statistical evaluation of experimental outcomes was processed with Design Expert software to find the optimum levels.

A first order polynomial regression equation that fitted the data is as follows

$\mathrm{Y}=\mathrm{b} 0+\mathrm{b} 1 \mathrm{X}_{1}+\mathrm{b}_{2} \mathrm{X}_{2}+\mathrm{b}_{3} \mathrm{X}_{3}+\mathrm{b}_{12} \mathrm{X}_{1} \mathrm{X}_{2}+\mathrm{b}_{13} \mathrm{X}_{1} \mathrm{X}_{3}+\mathrm{b}_{23} \mathrm{X}_{2} \mathrm{X}_{3}+\mathrm{b}_{123} \mathrm{X}_{1} \mathrm{X}_{2} \mathrm{X}_{3}$ (1)

Here b0 is the arithmetic mean of all the quantitative outcomes of the eight experimental runs; $b_{1}-b_{3}$ are the estimated coefficients from the observed experimental values of $\mathrm{Y}$ for $\mathrm{X}_{1}, \mathrm{X}_{2}$, and $\mathrm{X}_{3}$. The interactions terms $\mathrm{Xi} \mathrm{XjXk}(\mathrm{i}, \mathrm{j}$, and $\mathrm{k}=1,2$, and 3 ) shows how the change in response occurs when two or more factors are simultaneously changed. The equation represents the quantitative effect of factors upon the each of the responses. A positive sign in front of the terms indicates a synergistic effect while a negative sign indicates an antagonistic effect of the factors. The significance of the model was estimated by applying analysis of variance (ANOVA) at the 5\% significance level. A model was considered significant if the $\mathrm{P}$ value was less than 0.05 . 


\section{Evaluation of Effect of Process Parameters on selected Responses and ANOVA analysis}

Note: In equation process variables Main compression force, Pre-compression force and turret speed to indicate as $\mathrm{A}, \mathrm{B} \& \mathrm{C}$ respectively.

\section{Weight Variation- (\% RSD)}

Weight variation in tablets occurs due improper flow of blend \& High turret speed. Weight variation was evaluated during all runs as per experimental design.

$$
\begin{aligned}
& \text { Weight } \quad \text { Variation } \\
& =+2.50+0.2787 * \mathrm{~A}+0.7488 * \mathrm{C}+0.1437 * \mathrm{ABC} \\
& \left(\mathrm{F}=302.33, \mathrm{P}<0.0001, \mathrm{R}^{2}=0.995\right)
\end{aligned}
$$

(RSD)

From equation it is observed that Main compression force and turret speed have positive effect on weight variation. Maximum effect observed in case of process variable Turret speed.

Same can be observed from Pareto chart (Fig. 1a), where main compression force and turret speed show effect more than Bonferroni limit showing almost certainly significant.

\section{Hardness and Thickness}

Main compression force and pre-compression force may have impact on Hardness of tablets which will have impact on drug product CQA.

Hardness $=+15.21+3.66 * \mathrm{~A}+0.4875 * \mathrm{~B}$

$\left(\mathrm{F}=268.67, \mathrm{P}<0.0001, \mathrm{R}^{2}=0.990\right)$

Thickness $=+7.02-0.1738 * \mathrm{~A}-0.0263 * \mathrm{~B}$

$\left(\mathrm{F}=453.26, \mathrm{P}<0.0001, \mathrm{R}^{2}=0.994\right)$

From equation it is observed that Main compression force and Pre-compression force have positive effect on hardness of tablet. Maximum effect observed in case of process variable Main compression force, same can be observed from Pareto chart (Fig.1b and 1c). For response thickness, main compression force showed negative effect i.e. increases in level of main compression force leads to decrease in thickness.

\section{Content Uniformity - AV value}

Unoptimized turret speed may have impact on content uniformity of final tablets, which will have impact on Assay of final tablets.

Content Uniformity $-\mathrm{AV}$ value $=+4.65+2.02 * \mathrm{C}$

$\left(\mathrm{F}=302.33, \mathrm{P}<0.0001, \mathrm{R}^{2}=0.994\right)$

From equation it is observed that turret speed has positive effect on content uniformity of tablets i.e. increase in turret speed leads to higher weight variation which finally impact on content uniformity of tablets.

Same can be observed from Pareto chart (Fig.1d), where turret speed show effect more than Bonferroni limit showing almost certainly significant.

5. Drug release in $0.1 \mathrm{~N} \mathrm{HCl}$ at $120 \mathrm{~min}$ and drug release in pH $6.5 \mathrm{SIF}$ at $15 \mathrm{~min}$.
Main compression force and pre-compression force may have impact on Hardness of tablets which will have impact on drug product CQA drug release.

Drug release in $0.1 \mathrm{~N} \quad \mathrm{HCl}$ at $120 \mathrm{~min}=$ $+5.63+2.63 * \mathrm{~A}+1.13 * \mathrm{~B}$

$\left(\mathrm{F}=24.62, \mathrm{P}<0.0001, \mathrm{R}^{2}=0.908\right)$

Drug release in $\mathrm{pH} 6.5 \mathrm{SIF}$ at $15 \mathrm{~min}=+68.13-4.13 * \mathrm{~A}$

$\left(\mathrm{F}=11.54, \mathrm{P}<0.0001, \mathrm{R}^{2}=0.65\right)$

From equation it is observed that Main compression force and Pre-compression force have positive effect on drug release in $0.1 \mathrm{~N} \mathrm{HCl}$. Increase in Main compression force leads to breakage of coating film around pellets which will have impact on drug release. Pareto chart (Fig.1e), also shows that main compression force t-limit is above Bonferroni limits showing certainly significant whereas pre-compression force showed limits above tlimit showing possibly significant.

In case of response Drug release in $\mathrm{pH} 6.5 \mathrm{SIF}$ at 15 min, only Main compression have significant impact (negative) same was observed in pareto chart (Fig.1f).

Optimization using regression analysis and validation of mathematical model

With the help of above mentioned mathematical models, process variables were optimized keeping the constraints in range to have design space. The optimum calculated parameters were

$\mathrm{X}_{1}$ : Main compression force: $11.33 \mathrm{kN}$

$\mathrm{X}_{2}$ : Pre-compression force: $2.72 \mathrm{kN}$

$\mathrm{X}_{3}$ : Turret speed: $23.56 \mathrm{rpm}$

The experiments were carried out according to the process parameters obtained after applying constraints, and the optimum solution with process parameters was evaluated for its considered responses. Results obtained for responses are shown in table 6. In order to evaluate the reliability of the mathematical model developed, three additional checkpoints were taken, and estimated using a generated model covering the entire experimental domain. Table 6 gives the levels of variables of optimum formulation and three random checkpoints with their experimental values, predicted values, and the percent bias.

For the optimum solution process parameters (Table 6), $\mathrm{Y}_{1}$ Experimental was 2.16 ( $\mathrm{Y} 1$ predicted, 2.22; percent bias, $0.06 \%), \mathrm{Y}_{2}$ Experimental was found to be 14.90 ( $\mathrm{Y}_{2}$ predicted, 15.68; percent bias,0.78), $\mathrm{Y}_{3}$ Experimental was found to be $6.97\left(\mathrm{Y}_{3}\right.$ predicted, 6.99; percent bias,0.02), $\mathrm{Y}_{4}$ Experimental was found to be $3.81\left(\mathrm{Y}_{4}\right.$ predicted, 3.77; percent bias,-0.04), $\mathrm{Y}_{5}$ Experimental was found to be $5.0\left(\mathrm{Y}_{5}\right.$ predicted, 5.74; percent bias,0.74) \& $\mathrm{Y}_{6}$ Experimental was found to be $68.0 \%$ ( $\mathrm{Y}_{6}$ predicted, 67.44; percent bias,-0.56) in the current study indicate the robustness of the mathematical model.

Based on above optimization studies, updated risk assessment was performed reducing the risk of evaluated process parameters on drug product CQA's from High to low and Medium to low shown in table 7. 
Table 6: The experimental and predicted values for evaluated responses $Y_{1}-Y_{6}$ along with percentage prediction error observed for optimum run (1) and random runs (2, 3 and 4).

\begin{tabular}{|c|c|c|c|c|c|c|c|}
\hline Number & $\begin{array}{c}\text { Main } \\
\text { compression } \\
\text { force }(k N)\end{array}$ & $\begin{array}{c}\text { Pre- } \\
\text { compression } \\
\text { force }(k N)\end{array}$ & $\begin{array}{l}\text { Turret } \\
\text { speed } \\
\text { (rpm) }\end{array}$ & $\begin{array}{l}\text { Response } \\
\text { variables }\end{array}$ & $\begin{array}{c}\text { Predicted } \\
\text { Values }\end{array}$ & $\begin{array}{l}\text { Experimental } \\
\text { values }\end{array}$ & $\begin{array}{c}\text { \#Bias } \\
(\%)\end{array}$ \\
\hline \multirow{6}{*}{1} & \multirow{6}{*}{11.33} & \multirow{6}{*}{2.72} & \multirow{6}{*}{23.56} & Y1 & 2.22 & 2.16 & 0.06 \\
\hline & & & & Y2 & 15.68 & 14.90 & 0.78 \\
\hline & & & & Y3 & 6.99 & 6.97 & 0.02 \\
\hline & & & & Y4 & 3.77 & 3.81 & -0.04 \\
\hline & & & & Y5 & 5.74 & 5.0 & 0.74 \\
\hline & & & & Y6 & 67.44 & 68.0 & -0.56 \\
\hline \multirow{6}{*}{2} & \multirow{6}{*}{13.00} & \multirow{6}{*}{2.00} & \multirow{6}{*}{15.00} & Y1 & 2.17 & 2.29 & -0.12 \\
\hline & & & & $\mathrm{Y} 2$ & 18.38 & 17.69 & 0.69 \\
\hline & & & & Y3 & 6.86 & 6.83 & 0.03 \\
\hline & & & & Y4 & 2.62 & 2.89 & -0.27 \\
\hline & & & & Y5 & 7.12 & 6.00 & 1.12 \\
\hline & & & & Y6 & 64.00 & 66.0 & -2 \\
\hline \multirow{6}{*}{3} & \multirow{6}{*}{9.38} & \multirow{6}{*}{3.48} & \multirow{6}{*}{22.97} & Y1 & 1.94 & 2.09 & -0.15 \\
\hline & & & & Y2 & 12.49 & 11.23 & 1.26 \\
\hline & & & & Y3 & 7.14 & 7.03 & 0.11 \\
\hline & & & & Y4 & 3.69 & 3.56 & 0.13 \\
\hline & & & & Y5 & 4.05 & 3.0 & 1.05 \\
\hline & & & & Y6 & 71.45 & 69.0 & 2.45 \\
\hline \multirow{6}{*}{4} & \multirow{6}{*}{12.61} & \multirow{6}{*}{2.51} & \multirow{6}{*}{22.97} & $\mathrm{Y} 1$ & 2.39 & 2.46 & -0.07 \\
\hline & & & & Y2 & 17.93 & 18.06 & -0.13 \\
\hline & & & & Y3 & 6.88 & 6.81 & 0.07 \\
\hline & & & & Y4 & 3.69 & 3.24 & 0.45 \\
\hline & & & & Y5 & 7.19 & 6.0 & 1.19 \\
\hline & & & & Y6 & 64.79 & 64.0 & 0.79 \\
\hline
\end{tabular}

Note: ${ }^{\#}$ Bias $(\%)=($ experimental value-predicted value $) /$ experimental value $\times 100$

Table 7: Updated Risk Assessment for Compression Process Variables

\begin{tabular}{|c|c|c|c|c|c|c|c|}
\hline \multirow[b]{2}{*}{ CQA's } & \multicolumn{7}{|c|}{ Compression Process steps } \\
\hline & $\begin{array}{c}\text { Tooling } \\
\text { design }\end{array}$ & $\begin{array}{c}\text { Feeder } \\
\text { speed }\end{array}$ & $\begin{array}{c}\text { Pre- } \\
\text { compression } \\
\text { force }\end{array}$ & $\begin{array}{c}\text { Main } \\
\text { compression } \\
\text { force }\end{array}$ & $\begin{array}{l}\text { Turret } \\
\text { speed }\end{array}$ & $\begin{array}{l}\text { Ejection } \\
\text { force }\end{array}$ & $\begin{array}{l}\text { Environmental } \\
\text { conditions }\end{array}$ \\
\hline \multicolumn{8}{|l|}{ Intermediate CQA's } \\
\hline Weight Variation & Low & Low & Low & Low & High & Low & Low \\
\hline Hardness & Low & Low & Low & Low & Low & Low & Low \\
\hline Thickness & Low & Low & Low & Low & Low & Low & Low \\
\hline \multicolumn{8}{|c|}{ Finished product CQA's } \\
\hline Assay & Low & Low & Low & Low & Low & Low & Low \\
\hline Dissolution & Low & Low & Low & Low & Low & Low & Low \\
\hline $\begin{array}{l}\text { Uniformity of } \\
\text { Dosage Units by } \\
\text { content } \\
\text { uniformity }\end{array}$ & Low & Low & Low & Low & Low & Low & Low \\
\hline Water content & Low & Low & Low & Low & Low & Low & Low \\
\hline $\begin{array}{l}\text { Related } \\
\text { Substances }\end{array}$ & Low & Low & Low & Low & Low & Low & Low \\
\hline
\end{tabular}




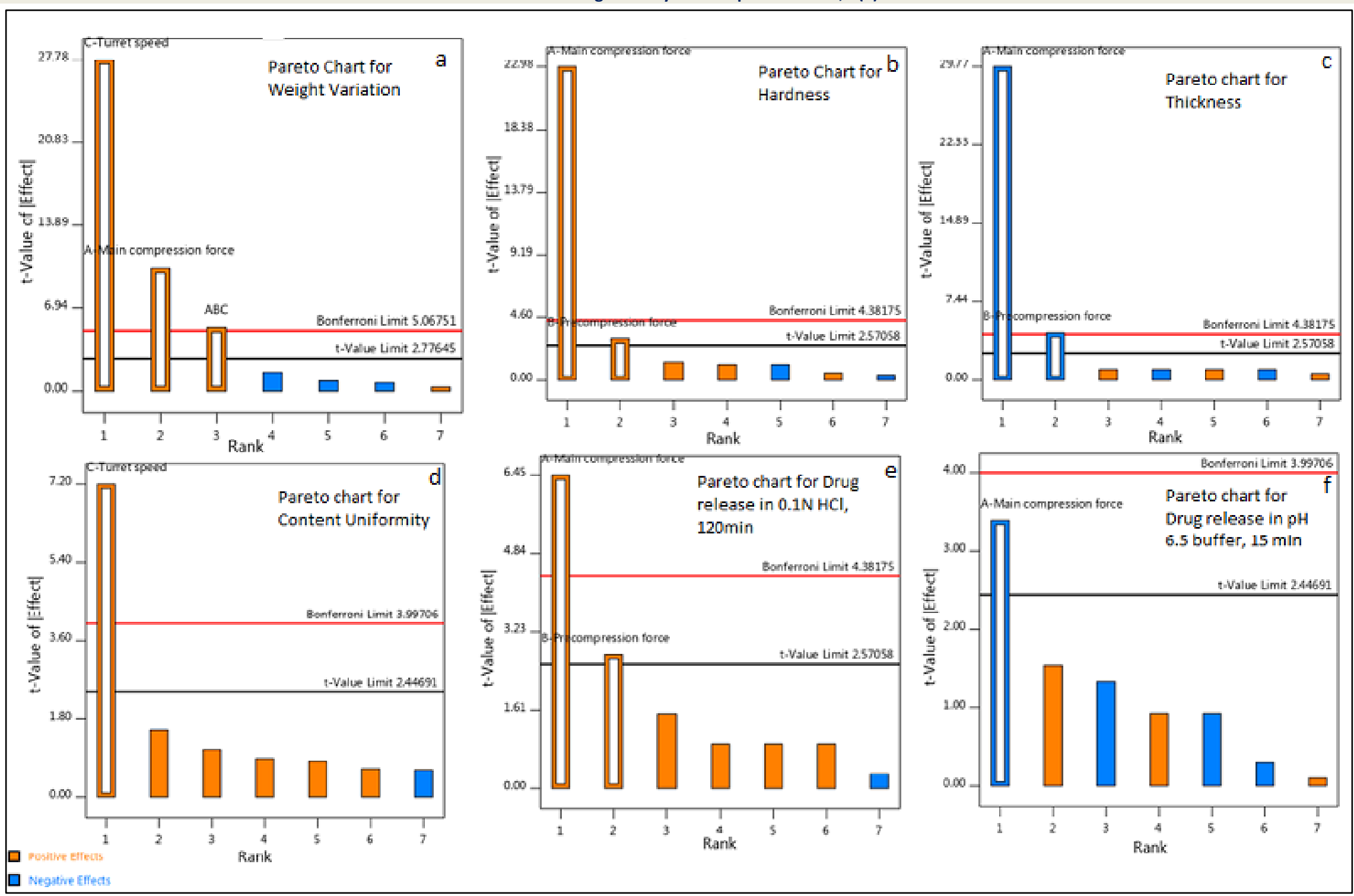

Figure 1: Graphical analysis by pareto chart for evaluation of effects on both the selected responses a) $\mathrm{Y}_{1}$, Weight Variation \% RSDb) $\mathrm{Y}_{2}$, Hardness c) $\mathrm{Y}_{3}$, Thickness d) $\mathrm{Y}_{4}$, Content Uniformity - AV value e) $\mathrm{Y}_{5}$, Drug release in $0.1 \mathrm{~N} \mathrm{HCl}$ at $120 \mathrm{min.f}$ ) $\mathrm{Y}_{6}$, Drug release in pH6.5 SIF, at $15 \mathrm{~min}$. 


\section{CONCLUSION}

Process optimization of Esomeprazole MUPS at compression stage was carried out using a three-factor, two-level, full factorial design. This allowed rapid evaluation and identification of the process parameters important in determining the desired responses. The impact of varying the levels of Main compression force, Pre-compression force and Turret speed on independent variables Viz. Weight variation - \% RSD, Hardness, Thickness, Content uniformity and Drug release was investigated. ANOVA analysis showed all models for selected responses were significant. The mathematical model for each of the responses developed using multiple regression analysis quantitatively describes the influence of the selected variables on the responses under investigation. Regression analysis showed $\mathrm{R}^{2}$ values more than 0.90 which indicates that the model explains all the variability of the response data around its mean. For optimized run observed responses were in close agreement with the predicted values, indicating excellent predictability of the optimization procedure.

The formulation with optimized process variables showed weight Variation- RSD: $2.16 \%$, Hardness:14.90Kp, Thickness: $6.97 \mathrm{~mm}$, Content uniformity: $\mathrm{AV}$ value -3.81 , Drug release in $0.1 \mathrm{~N} \mathrm{HCl}$ at 120min: $5.0 \%$ and Drug release in $\mathrm{pH} 6.5 \mathrm{SIF}$ at $15 \mathrm{~min}$ : $68 \%$ in the current study indicate the robustness of the mathematical model. From above studies, it is concluded that a quality Esomeprazole MUPS tablet was successfully evaluated designed using QbD approach for compression process variables.

\section{REFERENCES}

1. Dey NS, SMajumdar S, Rao MEB, Multiparticulate Drug Delivery Systems for Controlled Release, Tropical Journal of Pharmaceutical Research, 2008; (3):1067-1075.

2. Celik M, Compaction of Multiparticulate Oral Dosage Forms, Multiparticulate Oral Drug Delivery, New York: Marcel Dekker, 181-15.

3. Dashevsky A, Kolter K, Bodmeier R, Compression of pellets coated with various aqueous polymer dispersions, International Journal of Pharmaceutics, 2004; (279): 19-26.

4. Pati R, Kohli K, Shrivastava B, Compression and evaluation of extended release matrix pellets prepared by the extrusion/spheronization process into disintegrating tablets, Brazilian Journal of Pharmaceutical Sciences, 2012, (48).

5. Bodmeier R, Tableting of coated pellets. European Journal of Pharmaceutics and Biopharmaceutics, 1997; (43):1-8.

6. Bechgaard H, Nielsen GH, Controlled-Release MultipleUnits and Single-Unit Doses a Literature Review, Drug Development and Industrial Pharmacy, 1978; (4):53-57.

7. Branka I, Svetlana I, Gabriele B, Zorica D, Evaluation of Diclofenac sodium release from Matrix pellets compressed into MUPS tablets. Yaugaku Zasshi, 2009; 129:1375-1384.

8. Murthy Dwibhashyam VSN, Vijaya Ratna J, Key formulation variable in tableting of coated pellets. Indian Journal of Pharmaceutical sciences, 2008; (70):555-564.

9. Patil S, Yeramwar S, Sharma P, Bhargava A, Review of Recent Studies on Statistical Optimization In Drug Delivery Technologies, Journal of Drug Delivery \& Therapeutics; 2014; 4(5):58-6.

10. Patil S, Pund S, Joshi A, Shishoo CJ, Shahiwala A, Chronomodulated press-coated pulsatile therapeutic system for aceclofenac: optimization of factors influencing drug release and lag time, ChronoPhysiology and Therapy, 2011; $1: 1-10$.

11. Lewis GA, Mathieu D, Phan-Tan-Luu R, Pharmaceutical Experimental Design. New York, NY: Marcel Dekker Inc; 1999

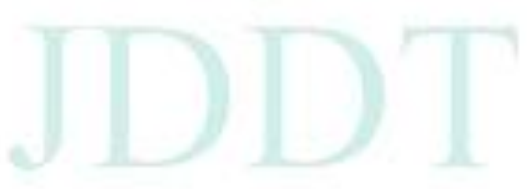

